\title{
Studies on the Nutritive Value and Chemical Quality of Different Commercial Grades of Oriental Sausage
}

\author{
Es raa B. EL-Saye d* and Abdelrahman, H. A** \\ Department of Food hygiene, Faculty of Veterinary Medicine, Suez \\ Canal University \\ *drbadr89@gmail.com **hrahman69@yahoo.com
}

\begin{abstract}
Egyptian Oriental sausage is one of the widely popular meat products. It is processed from a combination of different types of meat cuts or variant meat species minced with suitable amount of fat. Finally, cased into natural sheep gut casing. In order to evaluate the quality of Egyptian oriental sausage, 40 samples of fresh Egyptian Oriental sausage were collected from different sources according to their price and manufacture origin at Ismailia governorate. The proximate chemical analysis and histological examination were carried out. The percentages of moisture, protein, fat, ash, total solids, $\mathrm{pH}$ and red meat content were 58.82, 22.05, 6.83, 1.27,41.74, 5.6 and 78.0 respectively. All the samples from different sources were agreed with the $\boldsymbol{E S}: \mathbf{2 0 0 5}$ for proximate chemical composition with exception of $65 \%$ of moisture results were not matched with the ES. While the histological examination showed wide variations among the different grades categorized according to their origin and price. This examination declared that $50 \%$ of the products contain inflamed, edematous, low quality meat cuts, and $10 \%$ of the samples had infestation with cysticercoids.
\end{abstract}

Key wards : chemical analysis; oriental sausage; histological examination

\section{Introduction}

The word sausage is derived its name from the Latin word Salsus, which means preserved by salting. Oriental Egyptian sausage is one of the widely popular meat products. It is processed from a combination of different meat cuts which considered an important, nutritious and favored food item and is popular among youngsters. It is widely consumed allover Egypt owing to its easy preparation, distribution, and affordability. 
Furthermore, it is manufactured at butcher shops, meat processing plants, and even at home because of its simple procedure and available ingredients. In principle, oriental fresh sausage is not cured and actually comprises the mixtures of meats, fat and spices stuffed into natural casings with the intention that the consumer himself cooks them prior to serving. In many countries, they are manufactured on request in butcher shops. A precise formulation must be adopted to ensure that the final products fulfill the standard regulations. Batching is the initial step in the production where all of the ingredients are set out in the correct proportion before processing. Next, the meat chopped to the desired size and stuffed into natural casings. The chemical analysis is required to prove that the additives are approved by the Egyptian standards (1972/2005) which set limits regarding the amount of the additive and the proximal components percentages.

The Egyptian, oriental sausage can be adulterated by different ways as adding meat trimmings, offal, and unauthorized meat in addition to using illegal meat species (Mokhtaret al., 2018). The present study was planned to evaluate the chemical and histological quality of different grades of Egyptian oriental sausages collected from Ismailia city markets.

\section{Mate rials and Methods}

Total number of 40 samples of raw traditional Egyptian fresh sausage were collected from different localities of Ismailia governorate, Egypt and examined for their proximate chemical composition according to the methods recommended by $\boldsymbol{A O A C}$ (2010):

1. Determination of moisture content: All samples are placed in a drying hot air oven which was adjusted at $105^{\circ} \mathrm{C}$ till two successive constant weights were obtained.

2. Determination of protein content: The protein content was carried out by using the Kjeldahl digestion block Kjeldatherm unit and distillation systems Vapodest 50 s.

3. Determination of Fat Content:By using the Soxtherm Manager, extraction of fat content (catalogue No. 13-0012, Gerdhart, Königswinter, Germany).

4. Determination of Ash content by using a crucible in which the samples were dried and ashing procedures was carried out by using the high temperature muffle furnace at temperature between 500 and $600{ }^{\circ} \mathrm{C}$ 
5. Estimation of Total Carbohydrate Content:

Calculation of the total carbohydrate content was done by difference using the following formula:

Carbohydrate $\%=100-$ $($ Protein $\%+$ Fat $\%+$ Water $\%+$ Ash \%).
Calculation of Red Meat Content (McLean, 2007):

The calculation of red meat content (Fat Free Meat Content) was calculated according the following equation:

$$
\text { Red meat } \%=\frac{\text { Total Nitrogen } \%-\text { Non-Meat Nitrogen } \% \text { x } 100}{\text { NF }}
$$

Where: Non-Meat Nitrogen = carbohydrate \%× CNF 100 . $(\mathrm{CNF}=$ the Carbohydrate Nitrogen Factor $=0.02$ ). NF is the Nitrogen Factor 3.50AMC (2014).

\section{7- Histological examination} was carried out according to the method recommended by (Harem and Altun, 2018)

\section{Results and Discussion}

\section{Moisture \%:}

The moisture percent in the examined samples as given in Table (1) for min., max. and mean \pm S.E values were $53.81 \%$, $63.58 \%$ and $58.8 \% \pm 0.64$ respectively. These results obtained were nearly similar with those reported by Abdolghafour and Saghir (2014), Shahin (2016), and Rehab (2017) and higher than that recorded by Nouman et al. (2001) and Hamed (2001), $26(65 \%)$ of the moisture samples were not matched with the ES: No 1972 (2005).

\section{Protein \%:}

The results of as given in Table 1 revealed that the protein \% were $19.8,25.02$, and 22.05 \pm 0.33 respectively. The results recorded were nearly agreed with those reported by Salem (2013) and Shahin (2016). However, higher finding of protein contents were reported by Abdolghafour and Saghir (2014) and lower results were reported by EL-Nashi et al. (2005) Fath-ELbab et al. (2006) and Alina and Ovidiu (2007). The results of matched samples of protein \% with the $\boldsymbol{E S}: \mathbf{1 9 7 2}$ (2005) revealed that all samples examined met the Egyptian standards. These variations in the results were attributed to the amount binding, seasoning, in addition the amount and type of meat cuts itself used in manufacture.

3. Fat \%: 
The fat $\%$ in the examined Egyptian oriental sausage samples as given in table (1) for the min., max. and mean value \pm S.E were 5.296, 8.685, and $6.827, \quad \pm 0.213$ respectively.

\section{Ash\%:}

The ash\% of the examined sausage samples was 0.784 ,
1.947 , and
$1.272 \pm$
0.0812 respectively.

\section{Red meat value:}

The results showed that the red meat value in the examined samples were $75.0 ; 82.8$; and $78.6 \pm 1.68$ which were $100 \%$ matched with the ES. All samples examined lied in the range accepted by the $\boldsymbol{E S}$ : 1972 (2005). The calculation of the red meat content in meat products was carried out to determine the quality of the meat products and its content from lean meat, in order to detect adulteration by other source of protein rather than meat.

\section{Histological examination:}

The histological examination is carried out to identify whether there are unacceptable components included in the sausage batter and to obtain information about the kind of tissues found in accordance with the Egyptian standards. Moreover, difficulties in identifying non-skeletal ingredients are faced during processing since the processing steps often change the morphological pattern of the tissues. The histological evaluation of the Egyptian oriental sausage samples revealed that skeletal muscles, adipose, connective tissues, blood vessels, nerves and glandular and spongy tissues were found. The kind and quality of the ingredients used in the manufacture of oriental sausages are governed by several factors, such as consumer demands, trading competition, and economic ground. The economic ground is the concept by which the producer may choose to allocate special cuts and parts of a carcasses considering the final coast.

On comparing connective proteins with that of myofibrillar proteins, it's of low nutritional value as it lacks some of the essential amino acid and less accepted, the protein content of beef skeletal muscles is higher than the protein content of the internal organs so addition of internal organs to the manufactured products will lower their nutritional quality and cold be detected histologically. On comparing the obtained results (images $1,2,3,4,5$ and 6) with that recommended by the ES:1972 / 2005 could categorize the results into two main groups:

\subsection{Processing plant products:}


Due to the wide commercial range it could be divided into:

\subsubsection{High commercial grade products}

which were around 100 LE per kilogram:

They are illustrated in image number 1 and 2 .

The results given in image (1) showed histological evaluation of the examined samples of Egyptian oriental sausage that contains Cucumber seeds, Pea seeds, Onion leaves, Root of plants, irregularly arranged collagenous and elastic fibers, food additives, spongy bone, and fibrous connective tissue.

The results given in image (2) it showed that all samples contain Skeletal muscle, Adipose tissues. There are degenerative changes in some areas of skeletal muscles due to heat processing in addition to Spindle-shaped smooth muscles of internal hollow organs, Fascia of irregular arranged collagenous fibers.

\subsubsection{Low commercial grade products:}

(which were around 30 LE per kilogram)

They are illustrated in image number 5

The results given in image (5) named Photomicrographs of unauthorized animal tissues in Egyptian oriental sausage revealed Skeletal muscle fibers, Fibrous connective tissue, Adipose tissues, Spongy bone,
Peripheral nerve tissue, Fascia of irregular arranged collagenous fibers. Presence of parasitic infestation by Sarcocyst was detected within skeletal muscle fibers. The occurrence of Sarcocyst was only in (4)10\% of the total examined samples. It was found only in the samples of low commercial grade production plants.

On comparing the obtained results with that recommended by the ES:1972/ 2005 it was declared that this group samples contain skeletal muscles less than that recommended, however most of the examined samples contain excess of adipose tissue, non-skeletal tissues and gristly and spongy tissues. The Egyptian standard stipulate that fresh sausage should not contain the nonskeletal tissue.

6.2. Butcher shops

Divided into two categories

6.2.1. High commercial grade butcher shops

(ranged from 120 to 140 LE per kilogram)

It is illustrated in image number (6)

The results given in image (6) Photomicrographs of normal tissues in the examined Egyptian oriental sausage samples showed longitudinal and cross section of normal skeletal muscle fiber. which revealed a good quality product in accordance with the 


\section{Egyptian 1972(2005). \\ 6.2.1. Low commercial grade butcher shops}

(about 30 to 60 LE per kilogram)

They are illustrated in image number 3 and 4.

The results given in image (3)

Photomicrographs

unauthorized animal tissues and Herbal contents in Egyptian sausage. Feather, Glandular tissue and Cucumber seeds.

The results given in image (4) as Photomicrographs of unauthorized animal tissues in Egyptian sausage showed Food additives located among spongy bone and adipose tissue, blood vessels, Neuronal tissue. High magnification field revealed numerous stellate-shape neurons and Mass of ganglionic cells.

The histological analysis detected samples with hyaline and degenerative changes which revealed that the bad quality meat used in the manufacturing of oriental sausage which had come from animals which unauthorized slaughtered without veterinary inspection, which Substitute the primalmeat cuts by cheaper ones.

All the previous data indicates that the price of the ingredients used plays an important role in the final product. The group of pathological conditions and unauthorized constituents of images number $1,2,3,4,5$ resembles (20)50\% of the total samples. which declared that the samples contain skeletal muscles less than that recommended and most of the examined samples were contain excess of adipose tissue, non-skeletal tissues and gristly and spongy tissues.

\section{Conclusion}

The chemical analytical methods and histological examination are considered the most applicable means in identifying tissue types. The adulteration of the superior quality meat by inferior one is a common practice globally known. Knowing the histological structure besides the nature of other ingredients is important for the possible economic loss by fraudulence also to ensure that the processors readily acting with accordance with standards. In the light of the previous achieved results, it could be concluded that all the investigated Egyptian oriental sausage samples were adulterated and had unacceptable quality attribution from the histological point of view. The results revealed a wide variety of tissues in the histological examination and most of the examined samples are not compatible with the Egyptian Standards. 
Table (1): Proximate chemical composition of the Egyptian oriental Sausage

\begin{tabular}{|l|c|c|c|}
\hline \multicolumn{1}{|c|}{ Item \% } & Minimum & Maximum & Mean \pm S.E \\
\hline Moisture & 53.81 & 63.58 & $58.82 \pm 0.64$ \\
\hline Protein & 19.82 & 25.02 & $22.05 \pm 0.33$ \\
\hline Fat & 5.29 & 8.68 & $6.82 \pm 0.21$ \\
\hline Ash & 0.78 & 1.94 & $1.27 \pm 0.08$ \\
\hline Total solid & 37.11 & 47.15 & $41.74 \pm 0.66$ \\
\hline Red meat & 75.70 & 82.20 & $78.60 \pm 1.68$ \\
\hline
\end{tabular}

Table (2): Matched accepted and non-accepted samples according to ES (2005) No.1972

\begin{tabular}{|l|c|c|c|c|}
\hline \multirow{2}{*}{\multicolumn{1}{|c|}{ Item \% }} & \multicolumn{2}{c|}{ Matched } & \multicolumn{2}{c|}{ Not Matched } \\
\cline { 2 - 5 } & No & $\mathbf{\%}$ & No & \% \\
\hline Moisture & 14 & 35 & 26 & 65 \\
\hline Protein & 40 & 100 & 0 & 0 \\
\hline Fat & 40 & 100 & 0 & 0 \\
\hline Ash & 40 & 100 & 0 & 0 \\
\hline Red meat & 40 & 100 & 0 & 0 \\
\hline
\end{tabular}

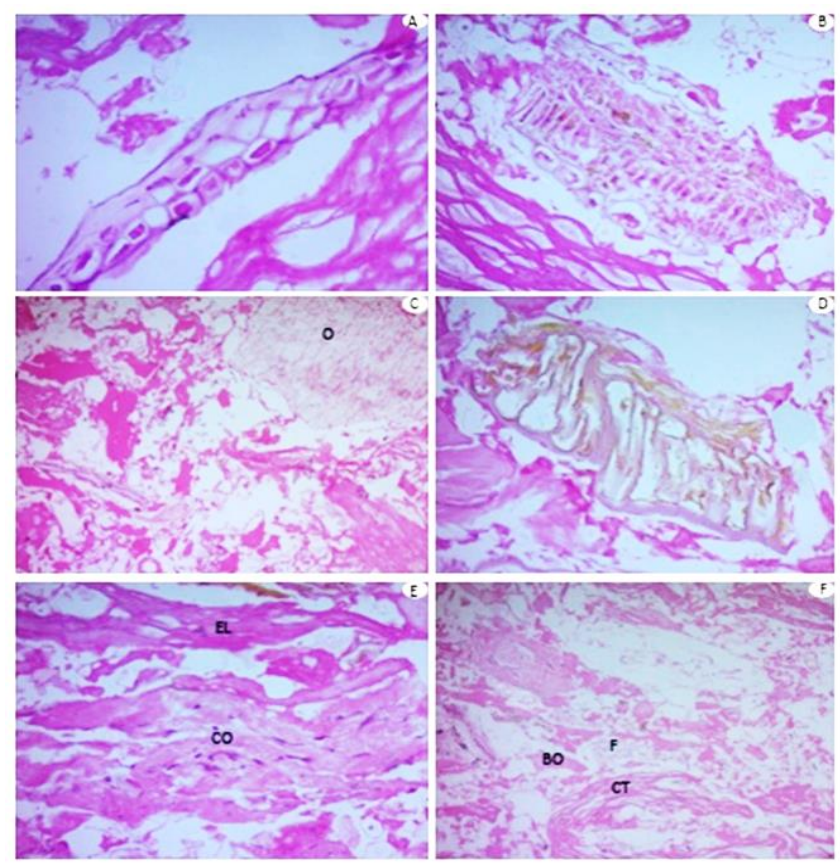

Figure 1 Photomicrographs of unauthorized plant contents in Egyptian sausage 


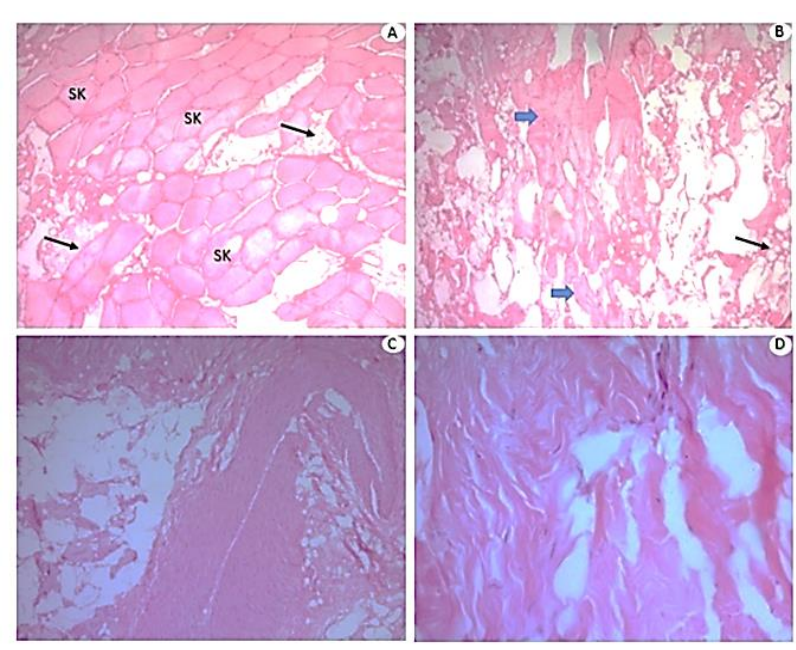

Figure 2 Photomicrographs showed degenerative changes and oriental sausage constituents.

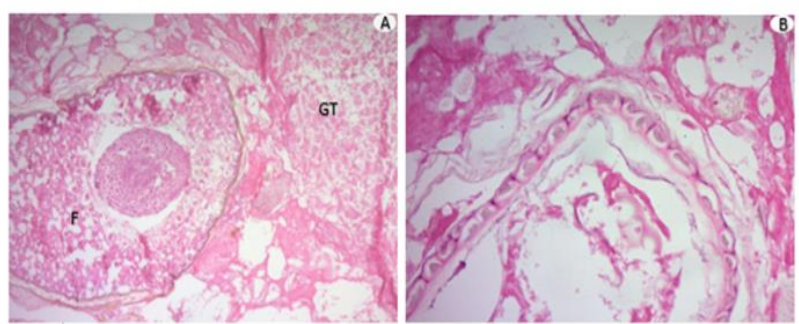

Figure 3 Photomicrographs of foreign tissues in the examined Egyptian oriental sausage

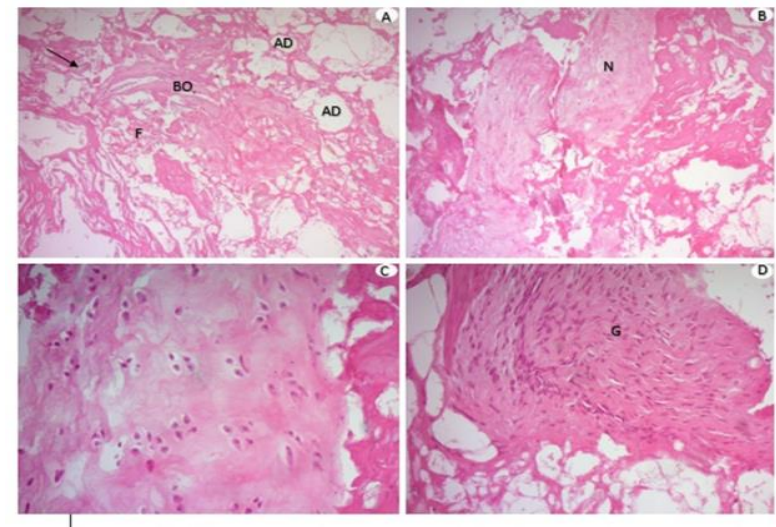

Figure 4 Photomicrographs of Neurons and Ganglionic cells in the components of the oriental Egyptian sausage 


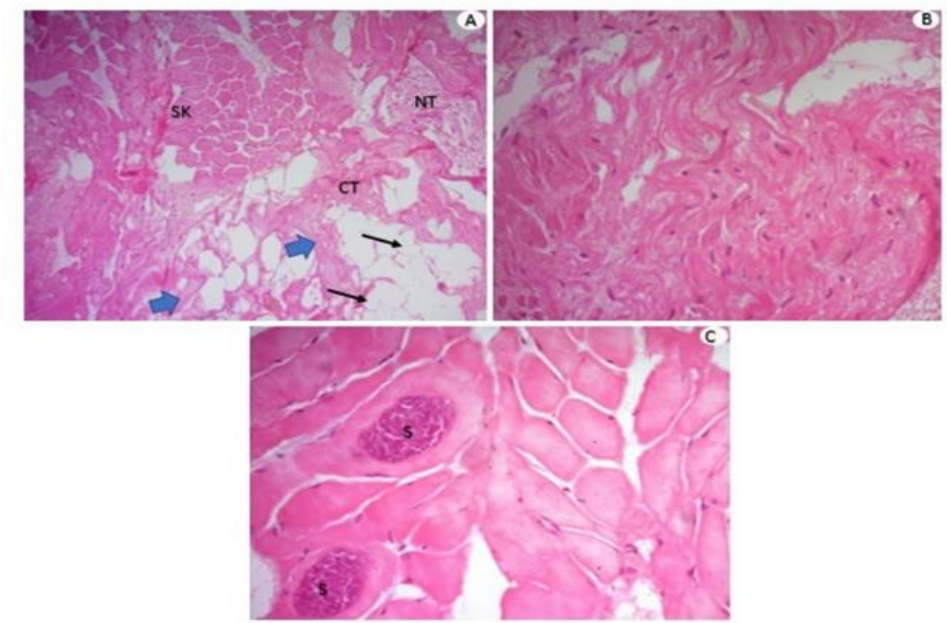

Figure 5: Sarcocyst in muscular tissues in Egyptian oriental sausage

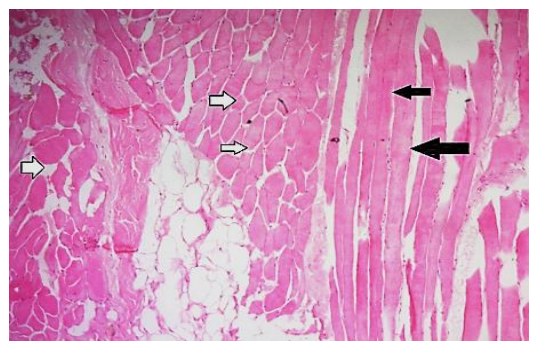

Figure 6: Photomicrographs of normal tissues in the examined Egyptian oriental sausage

References:

AOAC: Association of Official Analytical Chemists

Abdolghafour, B. and Saghir. A. (2014): Development in sausage production and practices-A review. Journal of Meat Science and Technology.

AMCAnalyst (2014), 125, 347351.

Alina, H. and Ovidiu, T. (2007): Determination of total protein in some meat products. American International Journal of Research. ISSN (Print): 23283734, ISSN (Online): 23283696.

Ayaz Y, Ayaz ND, Erol I (2006): Detection of species in meat and meat products using enzyme-linked immunosorbent assay. J Muscle Foods 17:214220.

B rian McLean (2007): Meat and meat products: the calculation of meat content, added water and connective tissue from analytical data. 
Campden \& Chorleywood Food Research Association Group

El-Nashi, H. B., Abdel Fattah A. A., Abdel Rahman, N. R. and M.M(2015): Abd characteristics of beef sausage containing pomegranate peels during refrigerated storage Annals of Agricultural Science (2015) 60(2), 403-412.

FathEL-Bab, G. F., Sayed E.M. and Ismail, T. H. (2006): bacteriological and chemical studies of frozen sausage in Giza province Zagazig Veterinary Journal, 34(1): 156_163.

Harem and Altun (2018): Histological investigation of fermented sausages sold in Sanliurfa province. International Journal of Scientific \& Technology Research 7(10):9699.

Hamed, M. I. A. (2001): Chemical evaluation of nonmeat ingredients in some meat products. MV Sc. Thesis, Food Control Department Assiut Vet Med. J. Vol 59 No. 139.

Mokhtar M.D., Abd-Elaziz M.D, Youss ef H., and Taha, A. (2018): Applied Histological and Chemical Analysis for Detection of Adulteration of Minced Meat and Sausage Journal of Advanced Microscopy Research Vol. 13, 1-9.

Nouman, T. Darwish, A.: Niazi, Z. and Aiedia, $H$. (2001): The

traditional Egyptian luncheon.1_Quality attributes of market product.

Veterinary medical journal ,49(2):199_210.

Rehab M. G (2017): Advanced Studies to Detect Commercial Adulteration in Meat Products at Ismailia Market. Ph. Thesis, faculty of Veterinary Medicine, Suez Canal University.

Shahin, M. F. S. A. (2016): Production of Ready to Eat Sausage by New Method. Volume :6 | Issue 3 Pages: 474478.

\section{Salem (2013): Quality} Characteristics of Beef Sausages with Tomato Peel as a Colour and Functional Additive During Frozen Storage. World Applied Sciences Journal 22(8):10851093 


\section{الملخص العربي}

يعد السجق الثرقي المصري من أحد منتجات اللحوم المشهورة والتي يتم تصنيعها بمزيج

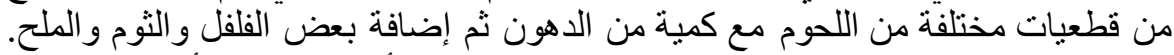

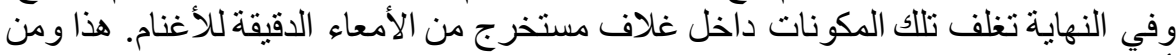

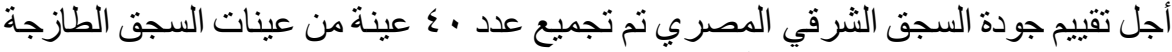

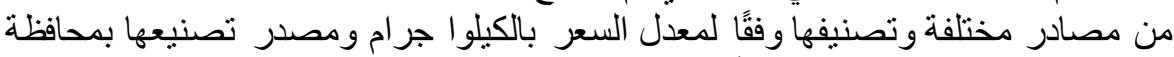

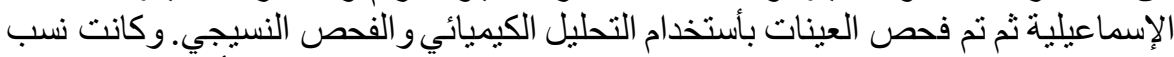

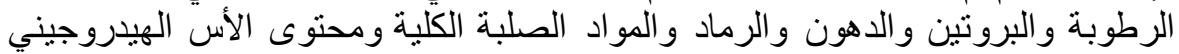

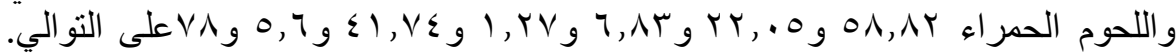

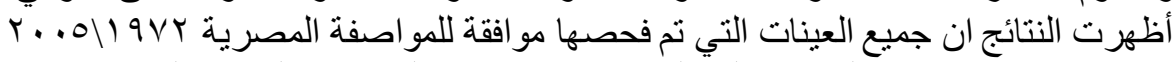

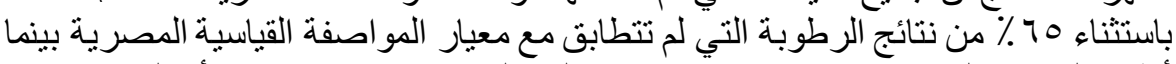

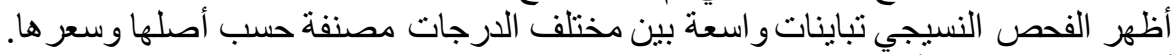

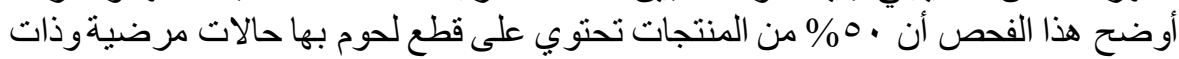

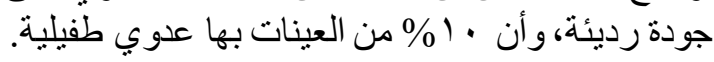

